\title{
Comparison of Various Precipitation Downscaling Methods for the Simulation of Streamflow in a Rainshadow River Basin*
}

\author{
Eric P. Salathé Jr. \\ Climate Impacts Group, \\ Joint Institute for the Study of the Atmosphere and Oceans / School of Marine Affairs, \\ University of Washington, Seattle
}

July 24, 2002

* Joint Institute for the Study of the Atmosphere and Ocean (JISAO) Contribution \#936 


\section{ABSTRACT}

Global simulations of precipitation from climate models lack sufficient resolution and contain large biases that make them unsuitable for regional studies, such as forcing hydrologic simulations. In this study, the effectiveness of several methods to downscale large-scale precipitation is examined. To facilitate comparisons with observations and to remove uncertainties in other fields, large-scale predictor fields to be downscaled are taken from the NCEP/NCAR reanalyses. Three downscaling methods are used: 1) a local scaling of the simulated large-scale precipitation 2) a modified scaling of simulated precipitation that takes into account the large-scale wind field, and 3) an analog method with 1000-mb heights as predictor.

A hydrologic model of the Yakima River in central Washington, USA, is then forced by the three downscaled precipitation datasets. Simulations with the raw large-scale precipitation and gridded observations are also made. Comparisons among these simulated flows reveals the effectiveness of downscaling methods. The local scaling of the simulated large-scale precipitation is shown to be quite successful and simple to implement. Furthermore, the tuning of the downscaling methods is valid across phases of the Pacific Decadal Oscillation, suggesting that the methods are applicable to climate-change studies. 


\section{Introduction}

Hydrologic models are an important tool in studying the effect of climate variability and change on water resources by simulating the streamflow associated with climate scenarios. A number of recent studies have attempted to link hydrologic models with climate scenarios (e.g. Bergström, et al., 2001, Leung et al., 1999, Hay, et al., 2000,). Daily temperature and precipitation are the principal atmospheric forcing parameters required for hydrologic studies, and a spatial resolution of 0.125 degrees latitude and longitude is generally sufficient to simulate monthly flow in mountainous river basins more than $10,000 \mathrm{~km}^{2}$ in size. Climate models, however, are run at much coarser resolution (typically 2 degrees or more) and do not resolve important mesoscale processes and surface features that control the regional precipitation. Thus, downscaling methods have been developed to span the gap from climate models to regional scales. In this paper, empirical methods to downscale precipitation will be compared in order to asses the quality of the resulting mesoscale precipitation for driving a hydrologic model.

Downscaling methods are reviewed in Wilby and Wigley (1997) and Giorgi et al. (2001). The downscaling methods presented here are statistical methods, and are based on empirical relationships between large-scale and mesoscale climate variables. Statistical downscaling may be contrasted to downscaling via a physical mesoscale model nested within the global model. Most statistical methods for precipitation downscaling are based on a large-scale predictor other than precipitation. A circulation parameter is the most common predictor, and often atmospheric moisture is considered as well (see Wilby and Wigley, 2000, for an overview of various

predictors for downscaling precipitation). The methods presented here, however, are based upon precipitation as the large-scale predictor, as motivated by Widmann and Bretherton (2000). A simple analog method based on circulation is also presented for comparison. Streamflow may 
also be directly downscaled from large-scale fields (e.g. Landman et al., 2001, Cannon and Whitfield, 2002).

The National Centers for Environmental Prediction/National Center for Atmospheric Research (NCEP/NCAR) reanalyses (Kalnay et al., 1996) shall be used as the large-scale predictor fields for this study, in an analogous manner to which a GCM would be used in a climate change study. In the reanalyses, precipitation is determined entirely by the large-scale model, not assimilated data. Thus the reanalysis precipitation is indicative of what a GCM might simulate if the large-scale fields such as temperature and heights are realistically simulated. By using the reanalyses as the large-scale predictors, the downscaling method may be verified against historical data with minimal interference from uncertainties in the simulated large-scale circulation. Several statistical methods for downscaling Pacific Northwest precipitation based on the NCEP reanalyses are proposed by Widmann et al. (2002) to produce monthly-mean precipitation downscaled to a 50-km mesoscale grid. Two of these methods are applied in a similar manner here to produce daily fields, as required by the hydrologic model. The relative skill of a mesoscale model and statistical methods for a small mountainous basin was evaluated by Wilby, et al., 2000, using a similar approach based upon the NCEP reanalyses. For simulations of the Animas River basin, Colorado, in that study, the statistical method was quite successful as compared to the mesoscale model.

In the Pacific Northwest region of the United States, the surface orography creates dramatically different precipitation zones over a horizontal distance smaller than a climate-model grid cell. Figure 1 shows the topography of the region; the dashed grid lines represent GCM resolution and the pixel size for the elevation map reflects the resolution of the hydrology model. The north-south oriented Coastal and Cascade Ranges create a powerful rainshadow. 


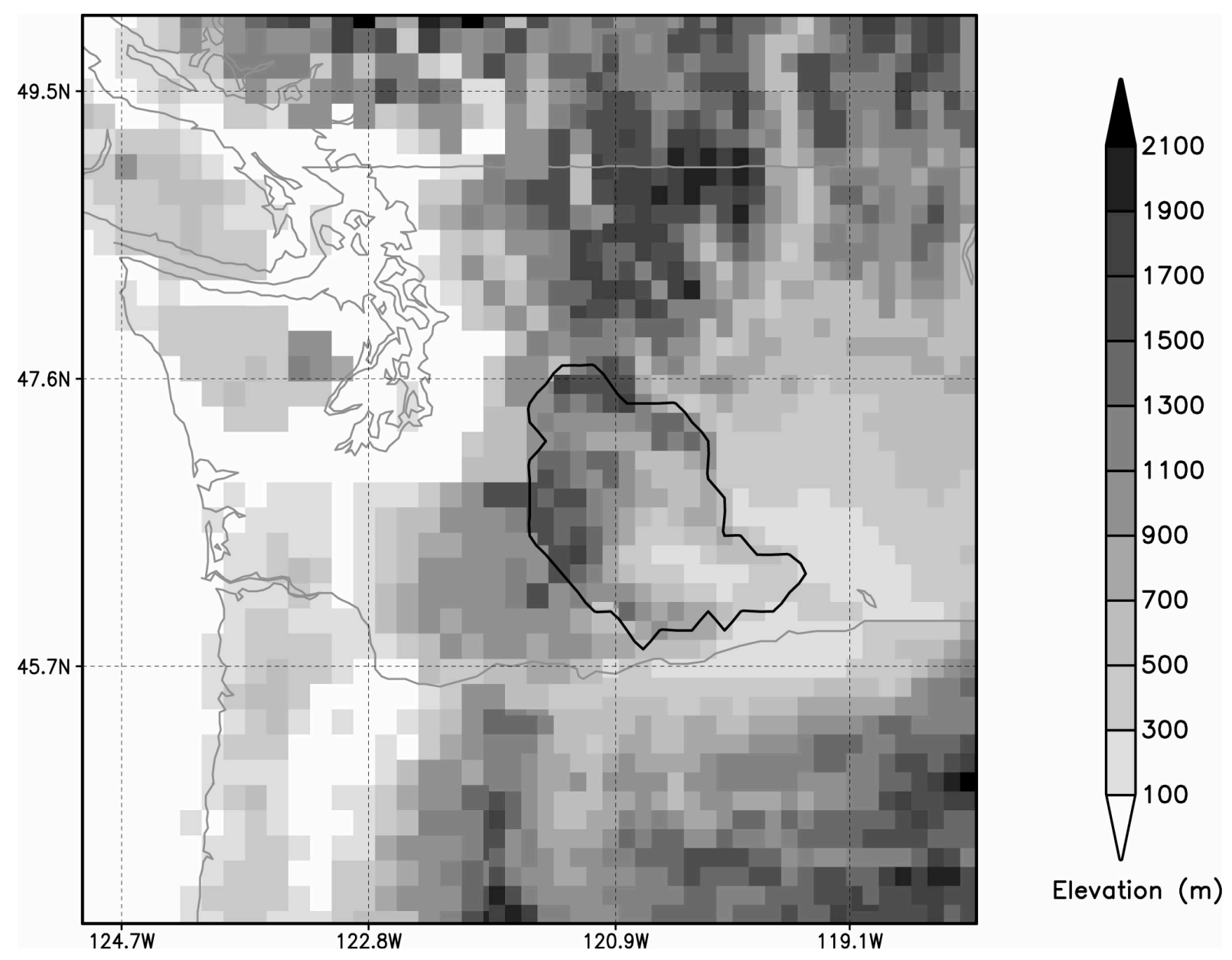

Figure 1 Elevation map of the study region, encompassing Washington and Oregon, USA. The heavy black line indicates the Yakima River basin. Thin dashed lines indicate the largescale grid. The hydrology model is run at the resolution indicated by the elevation pixels.

Considerable precipitation falls along the coast and Puget Sound region in the west while arid conditions prevail in the central Columbia Basin and high desert regions of Washington and Oregon to the east. Typical general circulation models (GCMs) do not resolve this topography, neither explicitly nor in subgrid-scale parameterizations, and thus cannot simulate the characteristic regional precipitation. In order to create precipitation fields sufficiently representative of actual conditions to force a hydrologic model, additional information must be added to the large-scale simulation through a downscaling method that accounts for the mesoscale variations. 
When the application of the downscaled precipitation is for hydrologic modeling, the skill of the method may not be accurately illustrated simply by comparing spatial patterns of precipitation. For example, the improved precipitation simulation of a more costly method may not be realized in the hydrologic simulation if the details are smoothed out over time and space by storage in snowpack or soil moisture. In many instances, the flow is simply a matter of total winter snow accumulation with temperature controlling the timing of melt and thus changes in flow. Alternatively, good temporal correlations and high spatial resolution over the region do not ensure that precipitation is properly distributed with respect to the topography or that there are no small local biases, which can have a critical effect on how the precipitation enters the hydrologic cycle.

In this paper, empirical precipitation downscaling methods are evaluated against their skill in driving a hydrological model of the Yakima River in central Washington, USA. The Yakima River originates on the east, leeward, crest of the Cascade Range in southern Washington. The basin is outlined in Figure 1, and is about the size of a single typical GCM grid cell. The river flows southeast to join the Columbia River. The basin spans an altitude range of about $2400 \mathrm{~m}$ and drains about $16,000 \mathrm{~km}^{2}$. The river is highly developed for hydropower and irrigation, and the natural flow is substantially controlled for these uses. The regional economy of the basin is based on agriculture and associated industry.

The Yakima provides a good test of the downscaling methods for several reasons. Significant precipitation events are associated with large-scale storm systems, so large-scale simulations have a good chance of representing the physical processes driving precipitation variability on the daily, monthly, and interannual timescales. However, the basin is only about the size of typical GCM grid cell and furthermore lies in the lee of the Cascade Range, which is typically not 
resolved by global models. Thus, we can expect GCM simulations or the NCEP/NCAR reanalyses will capture the dynamics that control precipitation but cannot simulate the regional patterns that depend on the interaction with local forcings, such as topography.

The seasonal flow pattern of the Yakima exhibits two peaks, one in fall when the seasonal precipitation maximum begins, but while it is still warm enough that some precipitation falls as rain, and a second peak in spring when the snowpack melts. These features are essentially mesoscale by nature as they are linked to the details of the topography. During the late fall when much of the precipitation occurs, only the higher elevation portions of the basin are below freezing. Depending on the timing of precipitation events relative to temperature and on the elevation where it falls, precipitation may fall as rain, producing a simultaneous peak in river flow, or fall as snow, and thus not contribute to runoff until the following spring. The relative magnitudes of these peaks and their timing varies considerably from year to year as a result both of temperature and precipitation variability. Thus, considerable additional information beyond what is in the reanalysis must be added by the downscaling method to simulate the annual cycle of flow.

The simulations that follow will illustrate how much is lacking in the raw NCEP precipitation, which is unsuitable for hydrologic studies. Considerable additional information may be added by simple downscaling methods yielding quite acceptable results. There are several other issues related to driving hydrologic models with large-scale atmospheric simulations, which are not addressed by this study. Notably, radiative effects, such as from variations in cloud cover, have a significant hydrologic influence. The approach considered here does not address all relevant issues of using large-scale models in hydrologic modeling, but rather focuses on the single issue of precipitation downscaling. 


\section{Data and methods}

\section{A. Downscaling}

For the purposes of this study, large-scale precipitation is taken from the NCEP/NCAR reanalyses (hereafter referred to simply as NCEP fields), which represents a "perfect" GCM in the sense that the daily large-scale circulation patterns and temperature are constrained to closely follow daily observations by the assimilation of data (Kalnay, et al., 1996). The reanalysis precipitation, however, is entirely model-generated, and simulates the precipitation that might occur with the actual large-scale conditions over much smoother boundary conditions than reality. In particular, the NCEP precipitation field is not forced by the true topography of the Cascade and Coastal Ranges, but captures only a gradual east-west gradient representing the western flank of the Rocky Mountains. Thus, there are severe biases in the NCEP precipitation, changing sign from too dry upwind to too wet downwind of the Cascades. Nevertheless, as shown by Widmann and Bretherton (2000), the NCEP precipitation is highly correlated in time to station observations after accounting for the local bias. The NCEP reanalysis grid is indicated by the dashed gridlines in Figure 1; note that the Yakima Basin overlaps two grid cells.

The observed mesoscale precipitation, used to fit the empirical methods, is from a $50-\mathrm{km}$ gridded dataset of daily precipitation over Washington and Oregon for 1949-1994 (Widmann and Bretherton, 2000). This dataset was produced from 522 daily station records adjusted for subgridscale topography to yield the long-term means from the Parameter-elevation Regressions on Independent Slopes Model (PRISM) (Daly et al. 1994). 

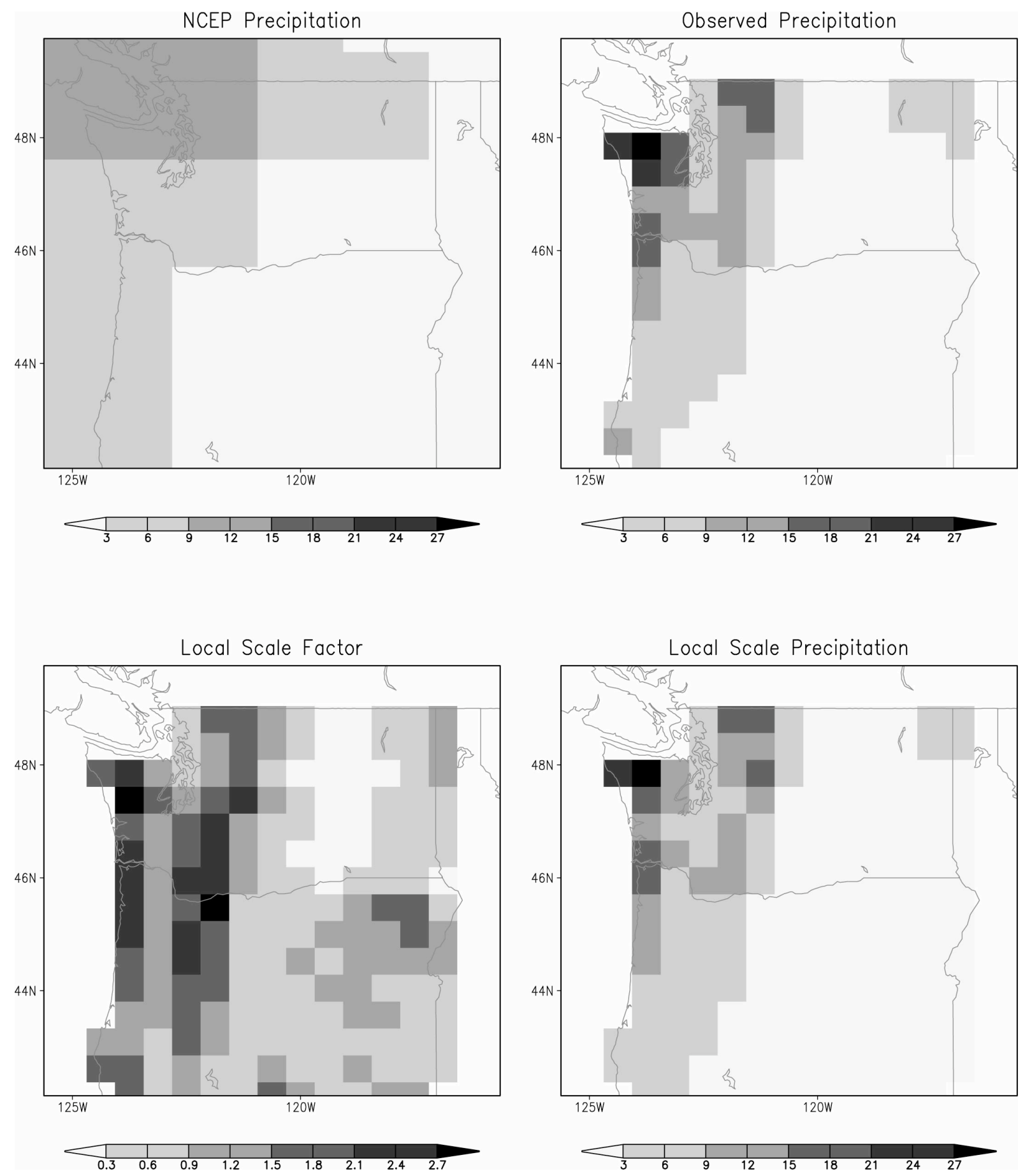

Figure 2. Upper left: The precipitation field from the NCEP/NCAR reanalysis for December 1990. Upper right: Gridded observations at $50 \mathrm{~km}$ for 1 Jan 1992. Lower right: Scaling factors used by the local scaling method for the DJF season. Lower right: Downscaled precipitation for the same period as upper panels. 
Two downscaling methods developed in Widmann et al. (2002) will be presented here. These are a local scaling and a dynamical scaling of the large-scale precipitation field. Each method represents downscaled precipitation as the product of the large-scale precipitation and a scaling factor that is resolved on the mesoscale grid. Results are also presented for a simple analog method using 1000-hPa heights as a predictor.

For the downscaling results presented here, the period 1958-1976 is downscaled using scale factors fit to the data for 1977-1994; likewise 1977-1994 is downscaled with scale factors fit to 1958-1976. This method alleviates the risk of over fitting the data. Furthermore, since the Pacific Decadal Oscillation was in opposite phases during these two periods, this division of the data indirectly illustrates the robustness of the method to shifts in the natural climate. Implications for this result will be discussed in Section 4.

In the case of downscaling a climate change simulation with a GCM, a control run of the GCM would be needed to derive the scaling factors for the local and dynamical scaling methods. Ideally, this would be a "historic" run with external forcings $\left(\mathrm{CO}_{2}\right.$, aerosol, solar input) matching the variations during the period of the observations. This approach assumes the mesoscale precipitation patterns are related to the large-scale precipitation in a similar way in current and future climates. Furthermore, it assumes that the climate-change signal is captured in the simulated large-scale precipitation and height fields.

\section{i. LOCAL SCALING}

In the local scaling method, the scaling factors are fixed for each three-month season and are simply the ratios $s=\langle p\rangle /\langle P\rangle$, where $p$ and $P$ are observed and NCEP precipitation respectively, and $\langle\cdots\rangle$ is the climatological seasonal mean over the fitting period at each grid point. Thus, the locally-scaled precipitation is constrained to have the same long-term seasonal mean as the 
observations at each 50-km gridpoint. The method relies on the fact that the NCEP precipitation is well correlated in time to the observations at any point even though it has quite large biases that vary from point to point (see Widmann and Bretherton, 2000). Figure 2 shows the monthlymean NCEP large-scale (upper left) and observed mesoscale precipitation (upper right) fields for 1 January 1992. The lower left panel shows the scaling factors for the December-JanuaryFebruary season (DJF). The lower right panel is the locally-scaled precipitation for January 1992, and is simply the product of the upper and lower left panels. The local scaling factor increases the simulated NCEP precipitation in the various mountainous regions and decreases it in the rainshadows.

\section{ii. Dynamical SCALING}

The dynamical scaling method is a modification of the local scaling where the effect of atmospheric circulation is taken into account, and the scaling factor depends also on the monthly-mean 1000-hPa heights. On the east side of the Cascades, the small amount of precipitation that does occur is highly dependent upon the atmospheric circulation, which modulates how much moisture is carried past the mountains. To illustrate the influence of circulation on the distribution of precipitation, consider variability associated with the leading mode of 1000-hPa heights, as revealed by EOF analysis. This mode is a modulation of the mean southwesterly onshore flow between a more southerly (Fig 3 left) and a more westerly (Fig. 3, right) phase. The composite precipitation pattern formed by averaging over all days of the first 1000-hPa phase shows more precipitation falls into the rain shadow during this phase (Fig 4, left). In comparison, the second phase is associated with drier conditions east of the Cascades and higher rainfall along the crest (Fig 4, right). Thus, the large-scale winds modulate the strength of the rainshadow. 

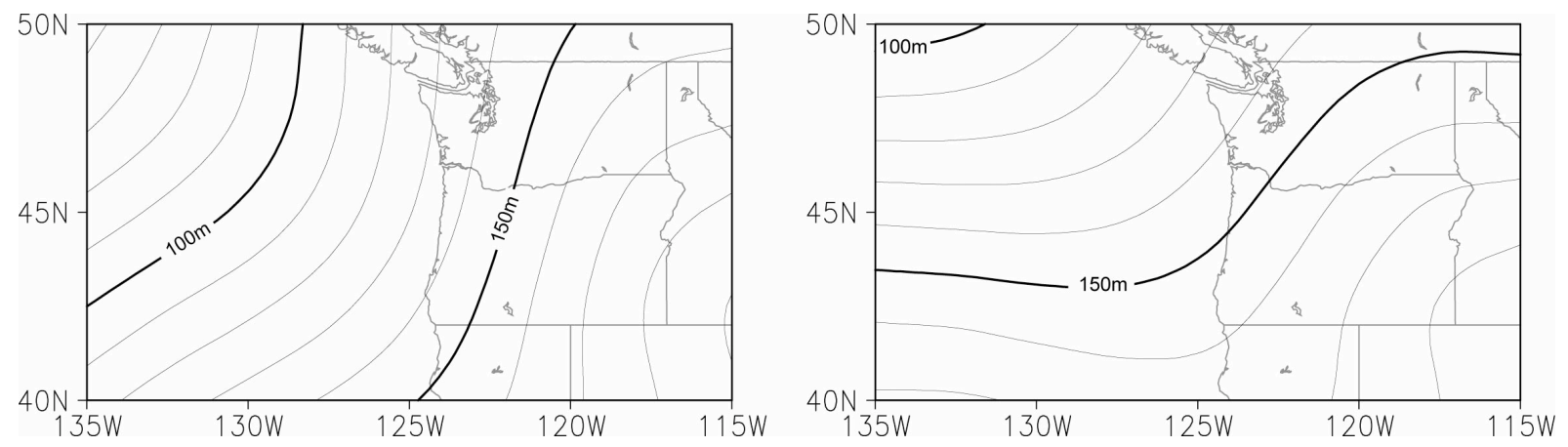

Figure 3. Two phases of the leading mode of variability of the 1000-hPa heights over the Pacific Northwest. Left: Average 1000-hPa height for days with positive phase of leading EOF. Right: Average over days with negative phase of leading EOF.
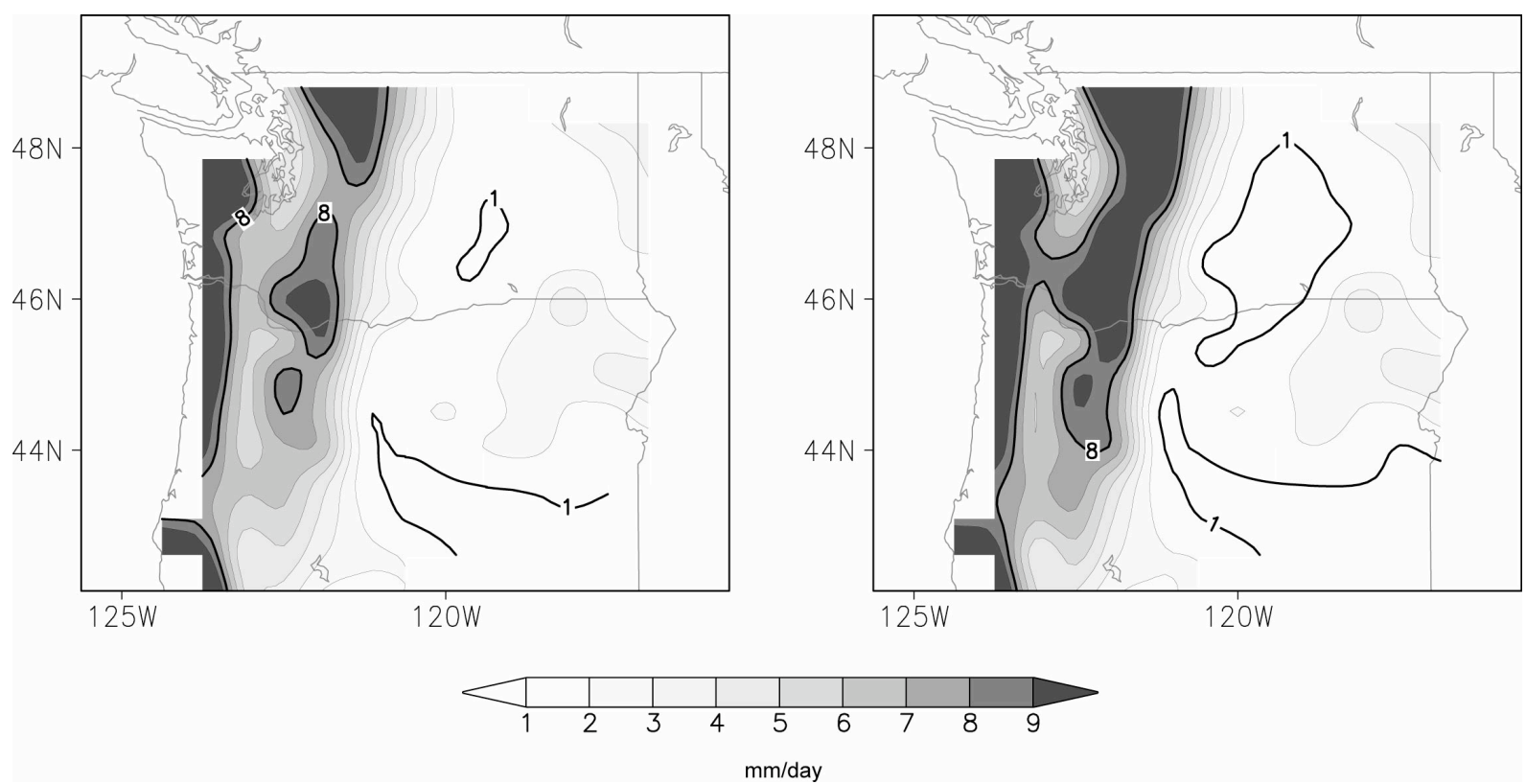

Figure 4. Observed precipitation composits for the two circulation patterns in Fig 3. The strength of the rainshadow is modulated by the variability in the height pattern, with less contrast across the Cascade Range on the left associated with more southerly flow and a high contrast on the right associated with more westerly flow

Similar dependence of the mesoscale precipitation distribution has been observed for South West England (Phillips and McGregor, 2001). Should climate change be associated with a shift in the statistics of the circulation patterns, this effect may have a significant effect on the 
climatology of rainfall that would not be captured by downscaling methods based solely on precipitation.

To account for the effect of circulation on the mesoscale precipitation field, the scaling factor is derived by constraining the covariance between downscaled precipitation and the leading three modes of the 1000-hPa heights to be the same as the covariance between observed mesoscale precipitation and leading 1000-hPa height modes, in addition to preserving the long-term mean. Thus, the downscaling is still performed by applying a high-resolution scaling factor, but the scaling factor now varies by month according to the simulated 1000-hPa heights. In this case, since we are testing the results for a "perfect" GCM, the NCEP reanalysis heights are used for both the observations and GCM, but in general, the GCM heights would be different. The first three EOF modes of the 1000 -hPa heights explain $52 \%, 32 \%$, and $8.5 \%$ of the variance in the DJF season, so truncating at three modes captures $92.5 \%$ of the total variance; results are similar for the remaining seasons. For a complete description of this method, see Widmann et al. (2002)

Figure 5 shows the correlation of the two downscaling methods with the observed precipitation at each gridpoint. Since the period 1958-1976 is downscaled with parameters tuned to observation for the period 1977-1994 and vice versa, the downscaled and observed time series are independent. Dynamical scaling (right) produces a significant improvement in the result over the dry region in the lee of the Cascades, indicating a strong control of the precipitation distribution due to circulation patterns. The Yakima Basin (outline region) falls along the edge of the area where the dynamical scaling improves the downscaling. There is little difference (less than 0.05) in the upper portion of the basin, where most of the rain and snow that supply the river falls. 


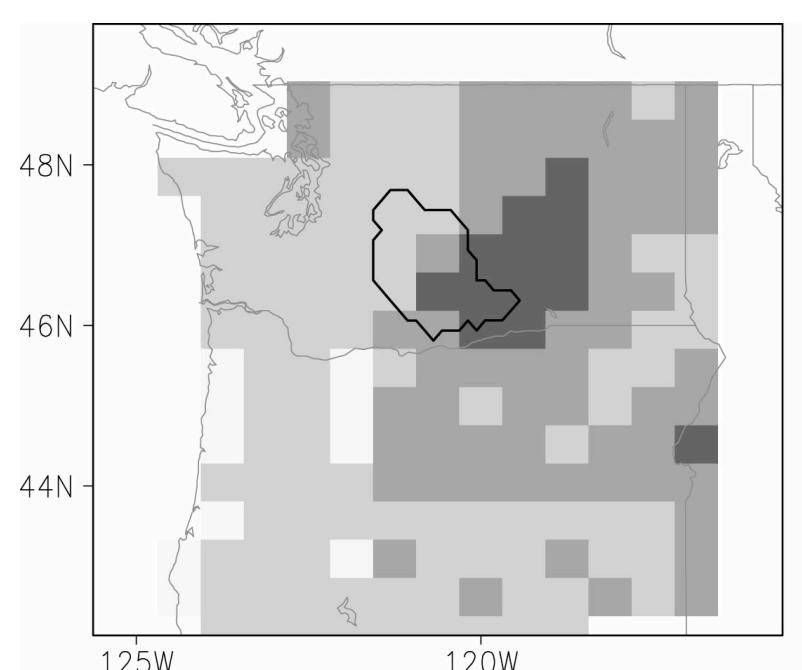

$125 \mathrm{~W}$

$120 \mathrm{~W}$

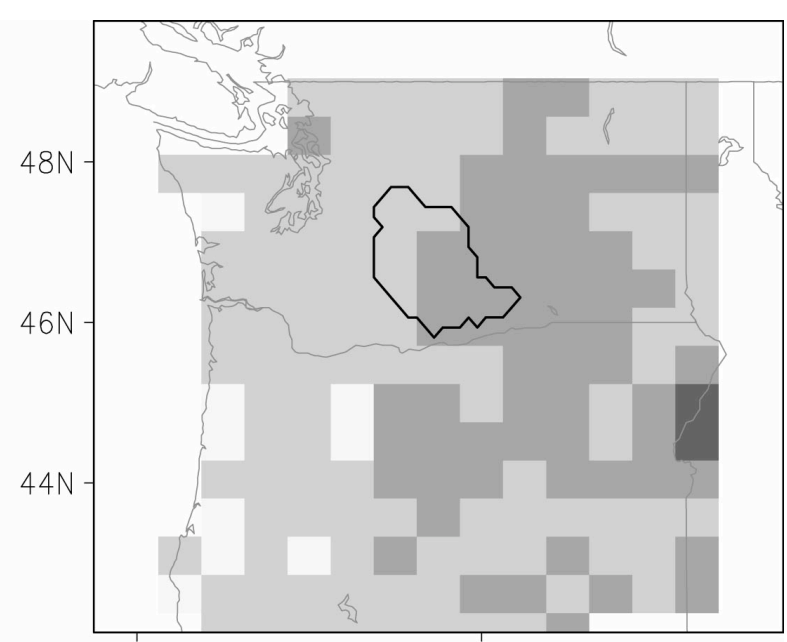

$125 \mathrm{~W}$

$120 W$

Figure 5. Temporal correlation of monthly-mean observed and downscaled precipitation at each gridpoint over the period 1958-1993. Dark areas indicate relatively poor correlations. Left: Local scaling. Right: Dynamical scaling

\section{iii. Analog Method}

For comparison, also presented are results of a simple analog method, with 1000-hPa heights as predictor. 1000-hPa heights are chosen as the predictor to illustrate the performance of a purely circulation-based downscaling method of comparable simplicity to the local scaling. The analog method is an attempt to find a day in the historical record that is an analog for each day in the large-scale simulation that is to be downscaled. The sequence historical analogs is not necessarily chronological.

With 1000-hPa heights as the predictor, the best historical analog is selected as that day when the observed heights (as indicated by the NCEP/NCAR reanalyses) most closely match the simulated heights. The best match is found by minimizing the sum of the mean-square difference between the amplitudes of the leading five EOFs of 1000-hPa height. Regional observations for the analog day, in our case, the gridded mesoscale precipitation, may then be assigned to the 
simulated day. In general, one would start with a GCM simulation of 1000-hPa heights and search the NCEP/NCAR reanalysis for the best match. In this study, we are using the NCEP/NCAR reanalyses as a surrogate for a GCM. Thus, to downscale a given day, we search for the best analog in years other than the one that contains this day. As with the scaling methods, this approach suggests how a perfect GCM, that accurately captures the well-resolved fields, would perform.

The downscaled precipitation from this method is correlated at 0.5-0.7 over the Yakima Basin, with higher correlations along the Cascade crest.

\section{B. Hydrology simulations}

In order to explore the implications of precipitation downscaling, streamflow simulations for the Yakima River were made for the period 1958-1993 using the Variable Infiltration Capacity (VIC) hydrology model (Liang et al., 1994) implemented at 0.125-degree resolution (Hamlet and Lettenmaier, 1999a). The 0.125-degree VIC model for the Columbia is very similar to the model implemented at 0.25 degrees described by Matheussen et al. (2000). Simulated grid cell runoff and baseflow is then processed with a river routing model (Lohmann et al, 1996, 1998) to produce streamflow in the Yakima basin. Data are presented for the magnitude of the flow where the Yakima River joins the Columbia River. The simulation is for unregulated flow, that is, the natural flow in the absence of any water management or groundwater interactions. Results of yearly total and monthly flows are presented for the period 1963-1993, allowing the first five years for model spin up. Each simulation is driven with a different precipitation dataset while temperature is the same observed maximum and minimum for each simulation.

For the simulation with observed precipitation, the VIC model is driven by the $50-\mathrm{km}$ precipitation dataset used to fit the downscaling methods, with a resolution of $0.48^{\circ}$ (lat) $\square$ 
$0.62^{\circ}$ (lon). The VIC model includes 0.125-degree precipitation data (Matheussen et al., 2000), which is derived from the station observations in the same manner as the $50-\mathrm{km}$ data. As noted in Widmann and Bretherton (2000), the 50-km grid provides on average 2 stations per grid cell and therefore grid-scale features are well resolved but sub-gridscale is not. Indeed, hydrologic simulations with the $50-\mathrm{km}$ data and the 0.125 -degree data are indistinguishable; monthly flows differ by less than a few hundredths of a percent. Thus, for the Yakima Basin, the 50-km spatial resolution is sufficient to reflect the available information in the station data.

In Widmann et al. (2002), monthly-mean patterns were downscaled. For this study, daily values are required to force the hydrology model, and the scaling factors are applied directly to the daily NCEP precipitation fields. Since the local and dynamical scaling methods cannot alter the number of wet days per month from what is predicted in the large-scale precipitation field, this approach only works where there is reasonable confidence in the daily variability of the predictor field. Widmann and Bretherton (2000) showed that, after removing the seasonal cycle, the daily NCEP precipitation time series is correlated at 54\% over the lower Yakima and at $73 \%$ over the upper Yakima Basin. Thus, the reanalysis captures realistic daily precipitation variability for this region. A free-running GCM, however, may not be able to simulate reasonable daily variability despite capturing reasonable monthly variability. In this case, it would be appropriate to downscale monthly means and apply another method to temporally disaggregate to the daily time step.

For comparison, two additional precipitation datasets are used: 1) The raw NCEP precipitation. As for the downscaling methods, the NCEP precipitation is taken as constant over each large-scale grid cell; not interpolated. Differences between this simulation and simulations using the downscaled precipitation illustrate the information added by the downscaling to the 
raw NCEP precipitation. 2) Daily climatological mean precipitation, which is formed by averaging the 50-km observed precipitation over 1958-1994 for each calendar day. The climatological precipitation is applied cyclically each year of the simulation, hence interannual variability is due only to the temperature forcing. Differences between other simulations and this "climate" simulation help separate the effects of precipitation and temperature variability.

$\begin{array}{ll}\text { Simulation } & \text { Precipitation Dataset } \\ \text { Lbserved } & \begin{array}{l}\text { Observed precipitation processed to 50-km grid } \\ \text { NCEP precipitation downscaled to 50-km grid using local } \\ \text { scaling method }\end{array} \\ \text { Dynamical Scale } & \begin{array}{l}\text { NCEP precipitation downscaled to 50-km grid using } \\ \text { dynamical scaling method }\end{array} \\ \text { Analog } & \begin{array}{l}\text { NCEP precipitation downscaled to 50-km grid using analog } \\ \text { method }\end{array} \\ \text { NCEP } & \begin{array}{l}\text { Raw NCEP precipitation } \\ \text { Climatology } \\ \text { precipitation applied cyclically }\end{array}\end{array}$

Table 1. Precipitation datasets for each hydrology simulation

In order to facilitate comparison of the various precipitation datasets without confusion of differing temperature time series, we drive all simulations with the same temperature data, the default 0.125 -degree VIC driving data. In general, correspondence between daily temperature and precipitation is essential to modeling the hydrology. Hence, taking temperature and precipitation from different sources for the NCEP and downscaling simulations may appear as a potential source of error. However, in the context for which the NCEP reanalysis is used here, the observed temperature, rather than assimilated temperature, is most appropriate. Since daily temperature observations are assimilated into the reanalysis, a successful downscaling of the large-scale NCEP surface temperature should return the observations.

The various simulations presented below differ only in the choice of precipitation data; observed temperature is used for each. Table 1 summarizes the different simulations. 


\section{Results}

In mountainous regions, where there is considerable storage in snowpack, streamflow is determined both by temperature and precipitation. Temperature variability controls the fraction of precipitation that contributes directly to runoff or is stored in the snowpack, the timing of the melt of the snowpack leading to spring flows, and evapotranspiration. Precipitation affects the total available water and also directly controls runoff and the resulting streamflow when the precipitation falls as rain. Flow in the Yakima River has two principal seasonal maxima, one due to melting of the high-elevation snowpack during early summer and a second due to rain in late fall.

Figure 6 shows the total water-year flows in the Yakima River at the point where it joins the Columbia River for the simulation period (a water year is the period from 1 October of the previous year to 30 September of the current year) from each simulation. The simulations with

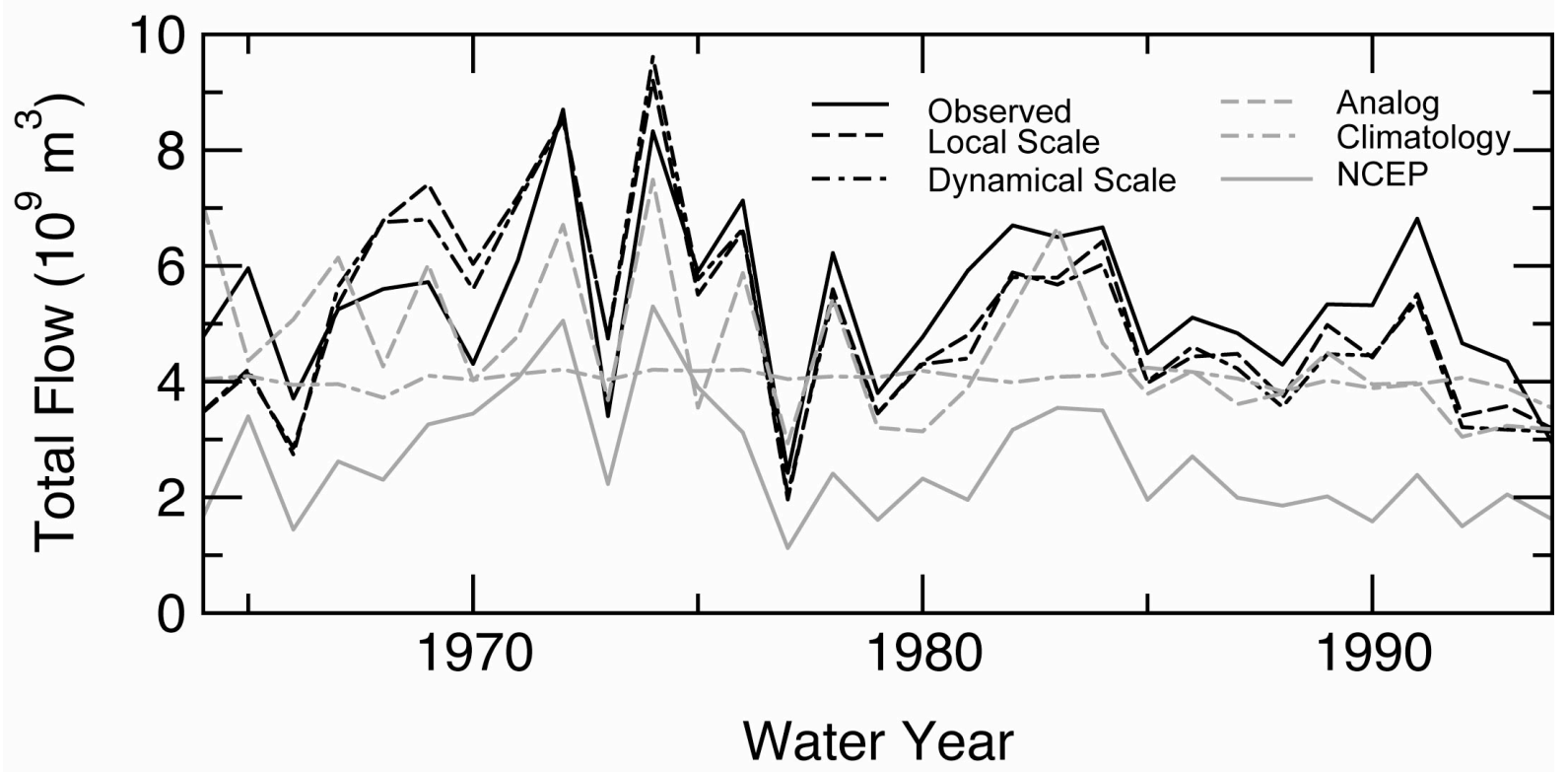

Figure 6 Total yearly flow simulated for the Yakima River using various precipitation data and observed temperature 
locally and dynamically scaled precipitation yield a good representation of the interannual variability, capturing sequences of wet and dry years. These two simulations, however, show a bias of excessive flow during the late 1960s and a bias of insufficient flow after 1980 relative to the simulation with observed precipitation. While the analog method does capture the major interannual features, it is considerably less capable than the other downscaling methods when compared to the observed simulation. The interpolated NCEP precipitation, in addition to yielding too little flow, also does not capture much of the observed interannual variability. That simulation misses, for example, the increased flows during 1966-68. Thus, downscaling is essential even in order to capture flow variability at interannual time scales.

\begin{tabular}{l|ll} 
Model & Correlation & Slope \\
\hline Local scaling & 0.84 & 1.00 \\
Dynamical scaling & 0.84 & 0.98 \\
Analog & 0.66 & 0.59 \\
NCEP & 0.79 & 0.58 \\
Climatology & 0.44 & 0.05
\end{tabular}

Table 2. Correlations with observed precipitation simulation for total annual flow

Table 2 shows the linear correlation and regression coefficient (slope) of total yearly flow for each simulation relative to the simulation with observed precipitation for the period 1963-1993. Correlation coefficients are all significant at the $99 \%$ level. The local and dynamical scaling methods perform equally well in capturing interannual variability. The analog method, however, does not add significantly to the raw NCEP precipitation although it does outperform climatology. Furthermore, the low value for the slopes indicates that the analog and raw NCEP precipitation do not produce the range of variability that the simulation with observed precipitation yields. 
By examining the flow on a monthly scale the details of the interannual variability are revealed. Figure 7 shows the monthly streamflow simulated with the model driven by observed precipitation, locally scaled precipitation, climatological precipitation, and NCEP precipitation. The date is the beginning of the water year, which falls on 1 October of the previous calendar year. The simulation for the dynamical scaling is not shown, but is indistinguishable from the local scaling on the graph. Variability in the simulation with climatological precipitation is due to interannual variations only in temperature, thus changes relative to the dotted line are due to differences in the precipitation datasets. While the local scaling simulation occasionally

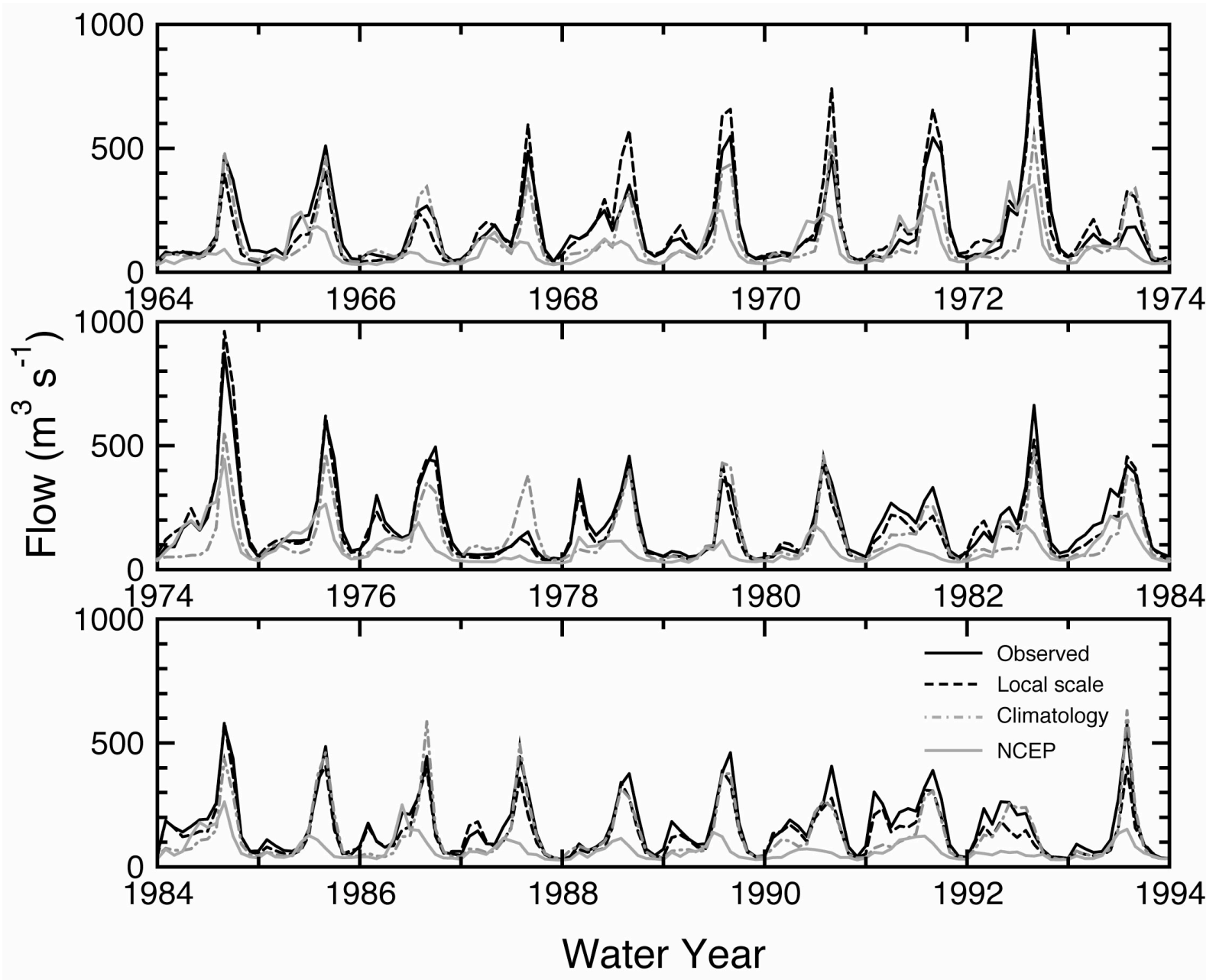

Figure 7. As for Fig. 6, but for monthly flow. 
overestimates streamflow relative to the observed simulation (e.g. water years 1968 and 1973), the main interannual features are well represented. For example, the local scaling can differentiate between years of a double-peaked flow (e.g. 1976, 1978, 1991) and years with a single, melt-driven peak (e.g. 1974, 1975, 1985). Also, low-flow (e.g. 1966, 1977) and high-flow (e.g. 1972, 1974) years are captured. These features do not appear in the simulation with climatological precipitation, indicating that the precipitation field, not temperature, generates them. The NCEP precipitation, in addition to a consistent dry bias, does not capture some of the significant seasonal features. For example, the double-peak in flow for the water years 1976 and 1978 is entirely missing in the raw NCEP simulation.

\begin{tabular}{l|l|l} 
Model & Correlation & Slope \\
\hline Local scaling & 0.94 & 0.96 \\
Dynamical scaling & 0.94 & 0.97 \\
Analog & 0.89 & 0.79 \\
NCEP & 0.64 & 0.29 \\
Climatology & 0.87 & 0.72
\end{tabular}

Table 3. Correlations with observed precipitation simulation for monthly flow

Table 3 shows the correlation and regression coefficient for the various methods to the observed monthly precipitation for the full period, 1963-1993. It is important to note that climatological precipitation combined with observed temperature yields a streamflow simulation $87 \%$ correlated to the simulation with observed precipitation, indicating the strong control of temperature on monthly variability and flow timing. As with the yearly total flow, the two scaling methods perform equally well for the Yakima basin and yield near ideal correlation. The analog method does no better than climatological precipitation, both in terms of correlation and slope. The raw NCEP precipitation does significantly worse, with marginal correlation and reduced variability. 
Compositing all years in the simulation illustrates the differences in the simulated annual cycle. In Figure 8, the curves indicate the monthly flow averaged over all water years (19641994) for the simulations using observed precipitation, locally scaled precipitation, and NCEP precipitation. The raw NCEP precipitation entirely misses the secondary flow peak in December. Furthermore, the peak flows occur in mid spring rather than in June. When the local scaling method is applied to the NCEP precipitation, however, these details of the annual cycle are faithfully simulated. Since the timing of precipitation events is the same in the NCEP and locally-scaled precipitation and since the temperature is the same, the only way the local scaling can produce these features is by amplifying the precipitation at high elevations where it is colder. More high-elevation precipitation creates a larger high-elevation snowpack that yields the summer flow peak. The total flow volume is also increased in the local scaling as the low precipitation bias in the NCEP precipitation is removed.

\begin{tabular}{l|ll} 
Model & Correlation & Slope \\
\hline Local scaling & 0.78 & 0.86 \\
Dynamical scaling & 0.79 & 0.89 \\
Analog & 0.57 & 0.56 \\
NCEP & 0.25 & 0.38
\end{tabular}

Table 4 Correlations with observed precipitation simulation for monthly flow, after subtracting the climatology simulation

Since temperature exerts a strong control on streamflow timing by forcing the melt of snowpack, even a relatively poor precipitation representation may yield reasonable results. If the results for climatological precipitation are subtracted from the other results, to produce an anomaly relative to the climatological precipitation simulation, the skill contributed by the precipitation dataset can be isolated somewhat from the temperature forcing. Table 4 shows results for correlation and regression of each anomaly against the anomaly for the observed 
precipitation simulation. The local and dynamical scaling both retain a significant correlation to the observed simulation, showing that considerable information about the mesoscale precipitation is captured. The analog method is marginally correlated while the raw NCEP analyses are essentially uncorrelated. Thus, most of the skill in the analog and NCEP simulations methods comes from the temperature field.

\section{Climate variability and downscaling}

The usefulness of a downscaling method depends on its ability to capture the effects of climate variability and change. This ability requires that 1 ) the predictor field captures the climate signal and 2) the connection between large-scale and mesoscale remains the same in a new climate state. The second requirement is more open to doubt for empirical methods, which are explicitly tuned to present climate conditions, than for physical models, although even physical models rely somewhat on tuning to present-day simulations.

In the Pacific Northwest, the marked climate variability produced by the Pacific Decadal Oscillation (PDO) (Mantua et al., 1997) creates an opportunity to test the downscaling method's ability to capture climate shifts. The PDO exhibits two phases; the positive or "cool" phase is associated with cool-wet conditions over the Pacific Northwest while the negative or "warm" phase is associated with warm-dry conditions. In the past century, the PDO underwent two full cycles. The PDO was in its cool phase from 1890-1924 and again from 1947-1976, and in its warm phase from 1925-1946 and from 1977 through the mid-1990's (Mantua et al. 1997, Minobe 1997). The PDO has a significant impact on snow pack and stream flows in the Pacific Northwest (Cayan 1996, Mantua et al. 1997, Bitz and Battisti 1999, Hamlet and Lettenmeier 1999b). 
As discussed above, in fitting the local and dynamical scaling methods, data from 1958 to 1976 were used to fit the period 1977 to 1994 and vice versa. Thus, the downscaling methods are tuned to data from the opposite phase from the phase where they are applied. The results in the above section illustrate that the tuning of the methods does transfer across the PDO phases, suggesting that the methods can be applied to future climates. Table 5 shows the same statistics as for Table 2 above, but with the data divided between the cool and warm PDO phases. The correlations for the downscaling methods remains as high or higher indicating that the methods are robust to the PDO climate regime change.

\begin{tabular}{l|cc|cc}
\multirow{2}{*}{ Model } & \multicolumn{2}{|c|}{ Cool (1963-1976) } & \multicolumn{2}{c}{ Warm (1977-1994) } \\
& Correlation & Slope & Correlation & Slope \\
\hline Local scaling & 0.82 & 0.99 & 0.94 & 0.81 \\
Dynamical scaling & 0.79 & 0.94 & 0.96 & 0.85 \\
Analog & 0.56 & 0.46 & 0.74 & 0.57 \\
NCEP & 0.83 & 0.61 & 0.78 & 0.42 \\
Climatology & 0.58 & 0.05 & 0.31 & 0.04
\end{tabular}

Table 5 Correlations with observed precipitation simulation for total annual flow for the periods of the cool and warm phases of the PDO.

In Figure 8, the annual cycle for the observed simulation during the cool PDO phase is shown by the solid upward triangles, and the warm phase by solid downward triangles. Upward and downward open triangles indicate cool and warm phases respectively for the local scaling simulation, while + and $\square$ are cool and warm phases for the NCEP simulation. The observed simulation shows the PDO signal of increased summer flow during the cool phase and reduced summer flow during the warm phase. The simulation with locally-scaled precipitation shows a similar signal to the observed simulation, although the response is slightly exaggerated. While the NCEP simulation cannot produce the annual flow cycle, it does produce a PDO signal in the 


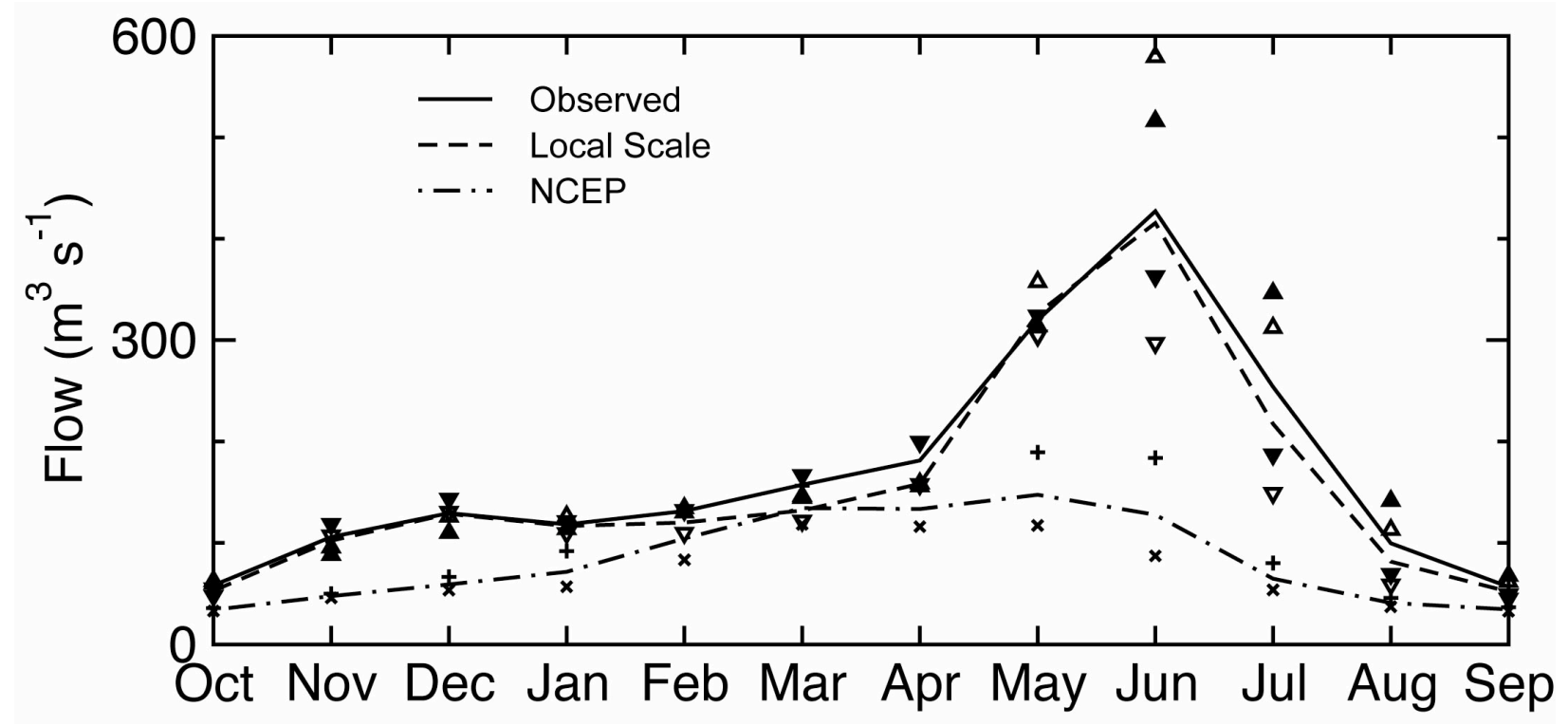

Figure 8 Annual cycle of flow in the Yakima formed by averaging all years in the simulation. precipitation simulation. Thus, simulated large-scale captures the climate signal associated with the PDO and transfers that signal to the downscaling method.

\section{Conclusions}

These simulations illustrate how local scaling, a very simple and efficient statistical downscaling method, is able to capture the essential precipitation features required for accurate simulation of flow in the Yakima River. The Yakima is in the dry rainshadow of the Cascades, and is subject to precipitation variability that is connected to the large-scale winds, as discussed in section 2A. Nevertheless, the quality of information needed to perform hydrologic simulations for present-day climate does not evidently require the additional detail provided by the dynamical scaling, which performs no better for driving the streamflow in this basin. Although the dynamical scaling considerably improves precipitation in the lower Yakima Basin, the upper part of the basin dominates the streamflow so that the deficiencies in the local scaling do not compromise the hydrologic simulation. However, the dynamical scaling may be significant in downscaling future climate scenarios even if it has little effect on downscaling historic data. 
Circulations statistics are relatively invariant between the fitting and downscaling periods in the study, so the local scaling may capture most of the signal. However, if there is significant alteration of the circulation in a future climate, the local scaling would not capture the effects. Furthermore, in a free-running GCM, the relationship between circulation and mesoscale precipitation may be worse than in the reanalysis, which does receive some indirect information about the lower boundary. In that case, the dynamical rescaling may also be more significant than indicated here.

The two scaling methods are as efficient and simple to implement as the analog method yet the analog method adds very little value to the raw large-scale precipitation for this region. One might expect an analog method, based on low-level winds, such as the one used here, would do well in this region where precipitation is controlled by large-scale storms and orography. Nevertheless, circulation alone evidently does not exert sufficient control to determine the precipitation variability, even within the present climate. A similar conclusion is suggested by precipitation-wind relationship in South West England (Phillips and McGregor, 2001). Using simulated precipitation and simulated circulation as predictors in the downscaling method includes both thermodynamic and fluid dynamic controls on precipitation.

It is clear that statistical downscaling can accomplish more than remove a uniform bias in a large-scale model simulation. The redistribution of water, implied by the scaling, can profoundly affect the hydrograph. Without downscaling, such significant a feature as the double-peaked hydrograph cannot be simulated with the unprocessed NCEP precipitation. The large-scale precipitation, however, does provide the interannual and interseasonal information needed to capture these features once it is scaled at high spatial resolution. 
In terms of the application of downscaling to climate change simulations, the scaling methods are not limited by past climate extremes. It is merely assumed that the bias remains the same in simulations of different climate states. The success of the methods across the PDO phase shift and the ability of the methods to capture the PDO impacts on streamflow support this assumption. Furthermore, these methods are easily calibrated to short runs of present-day climate. While the dynamical scaling method does not produce significantly different results from the local scaling for the present-day conditions considered here, it is possible that simulations of climate change may yield a shift in circulation that is not fully captured by the large-scale precipitation. The dynamical scaling allows more flexibility in the method to account for such climate shifts.

\section{Acknowledgements}

Alan Hamlet provided assistance in obtaining and running the VIC hydrology model. He and Andy Wood were responsible for much useful discussion and instruction on hydrologic modeling. This publication is funded by the Joint Institute for the Study of the Atmosphere and Ocean (JISAO) under NOAA Cooperative Agreement No. NA17RJ1232.

\section{REFERENCES}

Bergstroem, S., Carlsson, B., Gardelin, M., Lindstroem, G., Pettersson, A., Rummakainen, M., 2001. Climate change impacts on runoff in Sweden - Assessments by global climate models, dynamical downscaling and hydrological modeling. Climate Research, 16: 101-112 Bitz, C.C., and D.S. Battisti, 1999. Interannual to decadal variability in climate and the glacier mass balance in Washington, Western Canada, and Alaska. Journal of Climate, 12: 31813196. 
Busuioc, A., D. Chen, and C. Hellström, 2001. Performance of statistical downscaling models in GCM validation and regional climate change estimates: application for Swedish precipitation. International Journal of Climatology, 21: 557-578.

Cannon, A. J. and P. H. Whitfield, 2002. Downscaling recent streamflow conditions in British Columbia, Canada, using ensemble neural network models. Journal of Hydrology, 259: 136151.

Cayan, D. R., 1996. Interannual climate variability and snowpack in the western United States. Journal of Climate, 9: 928-948.

Daly, C., R. P. Neilson, and D. L. Phillips, 1994. A statistical-topographic model for mapping climatological precipitation over mountainous terrain. J. Appl. Met., 33: 140-158.

Gershunov, A., T. P. Barnett, D. R. Cayan, T. Tubbs, and L. Goddard, 2000. Predicting and downscaling ENSO impacts on intraseasonal precipitation statistics in California: The 1997/98 event. J. Hydrometeorology, 1: 201-210.

Giorgi, F., B. Hewitson, J. Christensen, C. Fu, M. Hulme, L. Mearns, H. von Storch, P. Whetton, and contributing authors, 2001. Regional Climate Simulation - Evaluation and projections. In IPCC WG1 Third Assesment Report, Cambridge University Press.

Hamlet, A. and D. Lettenmaier, 1999a. Effects of climate change on hydrology and water resources in the Columbia River Basin. J. Amer. Water Res. Assoc., 35: 1597-1623.

Hamlet, A.F., and D.P. Lettenmeier, 1999b. Columbia River Streamflow forecasting based on ENSO and PDO climate signals. American society of Civil Engineering, 25: 333-341.

Hay, L. E., R. L. Wilby, and G. H. Leavesley, 2000. A comparison of delta change and downscaled GCM scenarios for three mountainous basins in the United States. J. Amer. Water Res. Assoc., 36: 387-397. 
Kalnay, E., M. Kanamitsu, R. Kistler, W. Collins, D. Deaven, L. Gandin, M. Iredell, S. Saha, G. White, J. Woollen, Y. Zhu, M. Chelliah, W. Ebisuzaki, W. Higgins J. Janowiak, K. C. Mo, C. Ropelewski, J. Wang, A. Leetmaa, R. Reynolds, R. Jenne, and D .Joseph, 1996. The NCEP/NCAR reanalysis project. Bull. Amer. Meteor. Soc., 77: 437-471.

Kidson, J. W. and C. S. Thompson, 1998. A comparison of statistical and model-based downscaling techniques for estimating local climate variations. J. Climate, 11: 735-753. Landman, W. A., Mason, S.J., Tyson, P.D., and Tennant, W.J., 2001. Statistical downscaling of GCM simulations to streamflow. Journal of Hydrology, 252: 221-236.

Leung, L. R., A.F. Hamlet, D.P. Lettenmaier, and A. Kumar, 1999. Simulations of the ENSO Hydroclimate Signals in the Pacific Northwest Columbia River Basin. Bulletin of the American Meteorological Society, 80: 2313-2329.

Liang, X., D. P. Lettenmaier, E. F. Wood, and S. J. Burges, 1994. A simple hydrologically based model of land surface water and energy fluxes for general circulation models. J. Geophy. Res., 99: 14415-14428

Lohmann, D., R. Nolte-Holube, and E. Raschke, 1996. A large-scale horizontal routing model to be coupled to land surface parameterization schemes. Tellus, 48: 708-721

Lohmann, D., E. Raschke, B. Nijssen, and D. P. Lettenmaier, 1998. Regional Scale Hydrology: I. Formulation of the VIC-2L Model Coupled to a Routing Model. Hydrological Sciences Journal, 43, 131-141.

Mantua, N.J., S.R. Hare, Y. Zhang, J.M. Wallace, and R.C. Francis, 1997. A Pacific decadal climate oscillation with impacts on salmon. Bulletin of the American Meteorological Society, 78: $1069-1079$. 
Matheussen, B., R.L. Kirschbaum, I.A. Goodman, G.M. O’Donnell, and D.P. Lettenmaier, 2000. Effects of Land Cover Change on Streamflow in the Interior Columbia Basin. Hydrological Processes, 14: 867-885.

Minobe, S. 1997. A 50-70 year climatic oscillation over the North Pacific and North America. Geophysical Research Letters, 24: 683-686.

Murphy, J., 1999. An evaluation of statistical and dynamical techniques for downscaling local climate. J. Climate, 12: 2256-284.

Nobre, P., A.D. Moura, and L. Sun, 2001. Dynamical downscaling of seasonal climate prediction over Nordeste Brazil with ECHAM3 and NCEP's Regional Spectral Models and IRI. Bull. Amer. Meteor. Soc., 82: 2787-2797.

Phillips, I. D. and G. R. McGregor, 2001. The relationship between synoptic scale airflow direction and daily rainfall: a methodology applied to Devon and Cornwall, South West England. Theoretical and Applied Climatology, 69: 179-198.

Rummukainen, M., J. Räisänen, B. Bringfelt, A. Ullerstig, A. Omstedt, U. Willénen, U. Hansson, C. Jones, 2001. A regional climate model for northern Europe: Model description and results from the downscaling of two GCM control simulations. Climate Dynamics, 17: 339-359.

Widmann, M and C. S. Bretherton, 2000. Validation of mesoscale precipitation in the NCEP reanalysis using a new grid-cell precipitation dataset for the Northwestern United States. $J$. Climate, 13: 1936-1950.

Widmann, M, C. S. Bretherton, and E. P. Salathé, 2002. Precipitation downscaling over the Northwestern United States using numerically simulated precipitation as a predictor. $J$. Climate. 16: 799-816. 
Wilby, R.L. and T.M.L. Wigley, 1997. Downscaling general circulation model output: a review of methods and limitations. Progress in Physical Geography, 21: 530-548.

Wilby, R.L. and T.M.L. Wigley, 2000. Precipitation predictors for downscaling: observed and general circulation model relationships. International Journal of Climatology, 20: 641-661

Wilby, R. L., L. E. Hay, W. J. Gutowski, R. W. Arritt, E. S. Takle, Z. Pan, G. H. Leavsley, and M. P. Clark, 2000. Hydrological responses to dynamically and statistically downscaled climate model output. Geophys. Res. Lett., 27: 1199-1202.

Wood, A.W., Maurer, E.P., Kumar, A. and D.P. Lettenmaier, 2001. Long Range Experimental Hydrologic Forecasting for the Eastern U.S. J. Geophys. Res. 107: 4429-4444 